\title{
Initial sizing of a roadable personal air vehicle using design of experiments for various engine types
}

\author{
faeyoung Cha and Fuyeol Yun \\ Department of Aerospace Engineering, Sejong University, Seoul, Republic of Korea, and \\ Ho-Yon Hwang
}

Department of Aerospace Engineering and Convergence Engineering for Intelligence Drone, Sejong University, Seoul, Republic of Korea

\begin{abstract}
Purpose - The purpose of this paper is to analyze and compare the performances of novel roadable personal air vehicle (PAV) concepts that meet established operational requirements with different types of engines.

Design/methodology/approach - The vehicle configuration was devised considering the dimensions and operational restrictions of the roads, runways and parking lots in South Korea. A folding wing design was adopted for road operations and parking. The propulsion designs considered herein use gasoline, diesel and hybrid architectures for longer-range missions. The sizing point of the roadable PAV that minimizes the wing area was selected, and the rate of climb, ground roll distance, cruise speed and service ceiling requirements were met. For various engine types and mission profiles, the performances of differently sized PAVs were compared with respect to the MTOW, wing area, wing span, thrust-to-weight ratio, wing loading, power-to-weight ratio, brake horsepower and fuel efficiency.

Findings - Unlike automobiles, the weight penalty of the hybrid system because of the additional electrical components reduced the fuel efficiency considerably. When the four engine types were compared, matching the total engine system weight, the internal combustion (IC) engine PAVs had better fuel efficiency rates than the hybrid powered PAVs. Finally, a gasoline-powered PAV configuration was selected as the final design because it had the lowest MTOW, despite its slightly worse fuel efficiency compared to that of the diesel-powered engine.

Research limitations/implications - Although an electric aircraft powered only by batteries most capitalizes on the operating cost, noise and emissions benefits of electric propulsion, it also is most hampered by range limitations. Air traffic integration or any safety, and noise issues were not accounted in this study.

Practical implications - Aircraft sizing is a critical aspect of a system-level study because it is a prerequisite for most design and analysis activities, including those related to the internal layout as well as cost and system effectiveness analyses. The results of this study can be implemented to design a PAV.

Social implications - This study can contribute to the establishment of innovative PAV concepts that can alleviate today's transportation problems. Originality/value - This study compared the sizing results of PAVs with hybrid engines with those having IC engines.
\end{abstract}

Keywords Aircraft design, Constraint analysis, Initial sizing, Mission profile, Personal air vehicle, Roadable PAV

Paper type Research paper

\section{Nomenclature}

\section{Symbols}

$$
\begin{array}{ll}
e_{\text {straight wing }} & =\text { Oswald's span efficiency of straight wing; } \\
e_{\text {swept wing }} & =\text { Oswald's span efficiency of swept wing; } \\
\mathrm{AR} & =\text { aspect ratio; } \\
\wedge_{L E} & =\text { leading edge sweep angle; } \\
C_{L \alpha} & =\text { lift curve slope; } \\
\beta & =\text { Mach number parameter; } \\
\mathrm{k} & =\text { ratio of the two-dimensional lift curve slope to } 2 \pi ; \\
\wedge_{c / 2} & =\text { sweepback of the mid chord; } \\
C_{L 0} & =\text { lift coefficient at a zero angle of attack; }
\end{array}
$$

The current issue and full text archive of this journal is available on Emerald Insight at: https://www.emerald.com/insight/1748-8842.htm

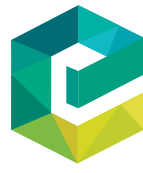

Aircraft Engineering and Aerospace Technology 93/11 (2021) 1-14

Emerald Publishing Limited [ISSN 1748-8842] [DOI 10.1108/AEAT-04-2020-0073]
$\alpha_{Z L}$
$\alpha_{C_{\text {max }}}$
$\alpha_{C}$
$C_{D_{0}}$
$\mathrm{D}$
$P_{B H P}$
RPM

(C) Jaeyoung Cha, Juyeol Yun and Ho-Yon Hwang. Published by Emerald Publishing Limited. This article is published under the Creative Commons Attribution (CC BY 4.0) licence. Anyone may reproduce, distribute, translate andcreate derivative works of this article (for both commercial and non-commercial purposes), subject to full attribution to the original publication and authors. The full terms of this licence may be seen at http://creativecommons.org/licences/by/4.0/legalcode

This work is supported by the Korea Agency for Infrastructure Technology Advancement (KAIA) grant funded by the Ministry of Land, Infrastructure and Transport (Grant 21CTAP-C157731-02).

Received 28 April 2020

Revised 21 January 2021

Accepted 11 February 2021 


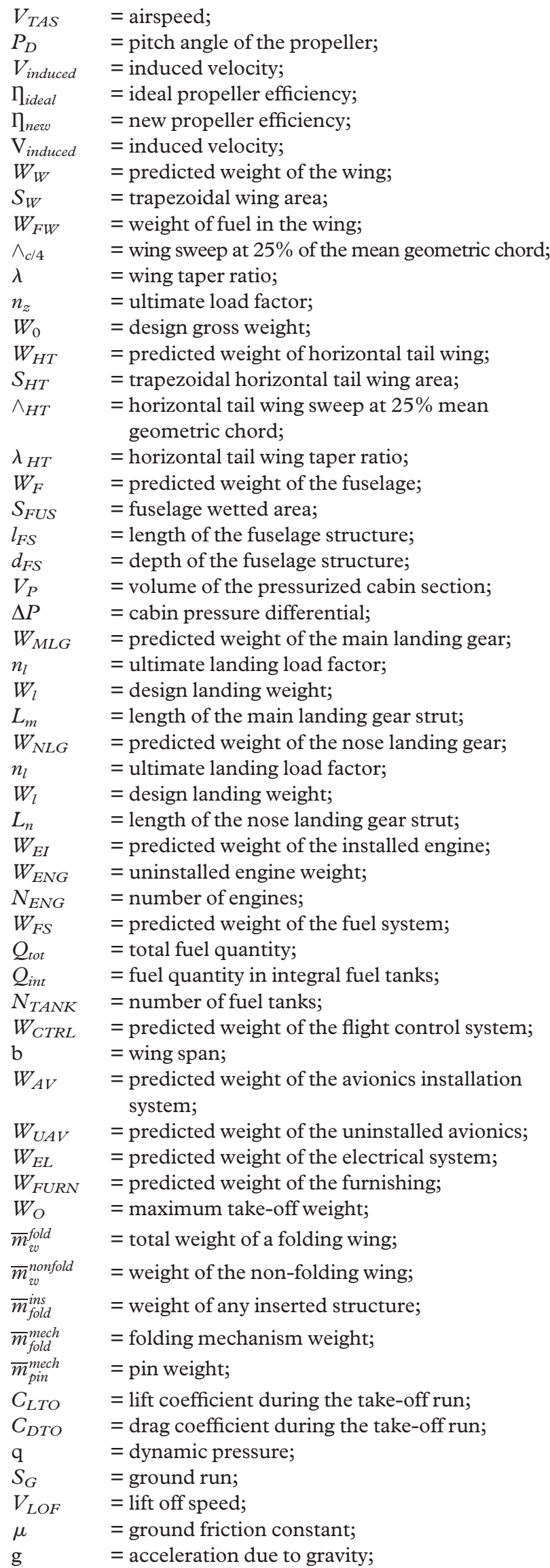

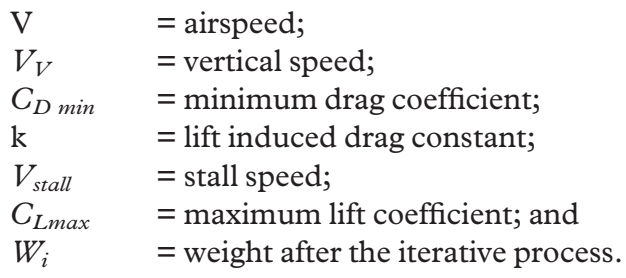

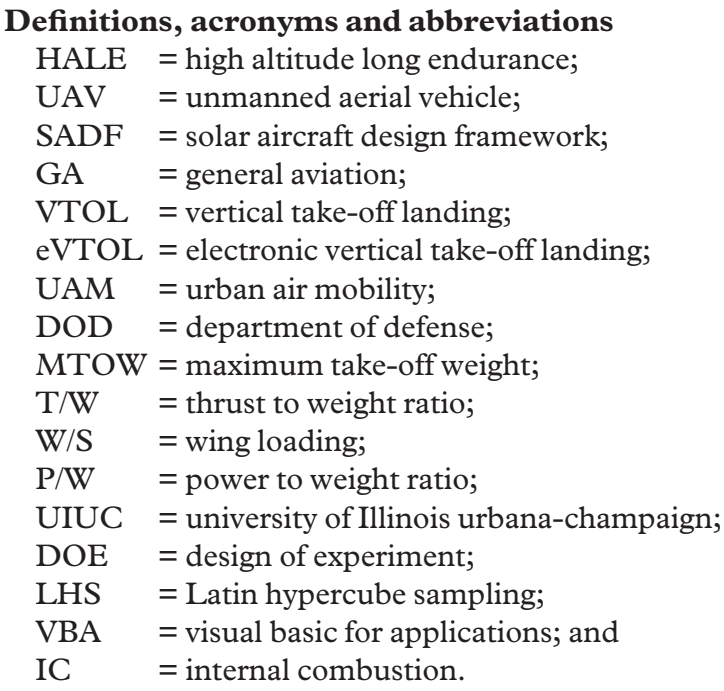

\section{Introduction}

The concept of door-to-door air mobility has long been a dream in the aerospace industry. As a potential means of providing the freedom of rapid door-to-door mobility beyond what is widely available today via automobiles, numerous roadable aircraft or flying-car concepts have been proposed, patented, built and flown during the past half century by inventors, entrepreneurs and military and civil research institutes (Lim et al., 2015).

However, personal air vehicles (PAVs) for transportation have not been developed in any significant way. A new style of transportation is essential to facilitate the movement of individuals from place to place without numerous complications. Furthermore, the current infrastructure must be considered such that a solution that can be seamlessly integrated into existing facilities and infrastructure, such as highways, roads, parking lots and airports, can be devised. The world's major cities are becoming increasingly overpopulated, and the land space available for ground transportation is becoming extremely limited. Therefore, air transportation may become more important in the future (Coronado et al., 2007).

Based on current requirements, the scientific community started to focus on general aviation (GA) and personal transport aircraft. NASA has recognized that personal air travel using an on-demand, highly distributed air transportation system would allow for improved mobility in congested areas in the USA. Therefore, they began research on this topic through the Small Aircraft Transportation System initiative (Viken et al., 2006), focusing on airspace-related issues considering the operation of PAVs. NASA has been investigating specific 
vehicle technologies in the PAV sector (Moore, 2006) under the Vehicle Systems Program (Vito et al., 2012).

There have been a number of attempts to combine a car and an aircraft into a single vehicle - referred to as a roadable aircraft. The Taylor "Aerocar" of 1949 (Aerocar, 2019) is an early example of this type of vehicle, with Carplane's road/air vehicle (Carplane, 2019) and Terrafugia's "Transition" (Terrafugia, 2019) bringing a modern approach to this concept. All these existing roadable aircrafts use a gasoline engine to drive pursher type propellers. Advantages of this type of vehicle are that it uses existing infrastructure and offers long ranges compared to vertical take-off landing (VTOL) PAV. In addition, the driving element of the operation will be familiar to existing road users.

To avoid using traditional runways and to provide the capability of potentially allowing flights from the user's home, one option for a PAV is to use a rotary wing aircraft, ideally without relying on the significant complexity and skill levels required to pilot a traditional helicopter configuration. The PAL-V (PAL-V, 2019) and Carter PAV (Carter, 2000) concepts both make use of autorotating rotors. The PAL-V concept combines an autogyro with road-driving capability. Vertical flight can be achieved in the Carter PAV concept by powering the rotor using the vehicle's engine and then performing a "jump take-off." Such a maneuver quickly puts a significant amount of energy into the rotor; therefore, a careful and robust design would be required to achieve acceptable levels of reliability and safety. This lifting approach incorporates a wide variety of propulsion concepts in an effort to gain greater propulsive efficiency and higher thrust-to-weight ratios. Due to the effects that different propulsion systems have on the overall design of the vehicles, a parallel approach with regard to the sizing the VTOL should be discussed.

Current transportation systems, represented by the centralized hub-and-spoke air transportation system and ground highway systems, are challenged in this era, during which time has become a scarce commodity. The establishment of innovative concepts that can alleviate today's transportation problems is becoming increasingly urgent ( $\mathrm{Li}$ et al., 2003).

Companies such as Airbus, Bell, Embraer, Joby, Zee Aero, Pipistrel, Volocopter and Aurora Flight Sciences are working with their battery vendors to build and test electric vertical takeoff and landing (eVTOL) aircraft to ensure that vehicle safety and energy efficiency become an integral part of people's daily commute. However, there is a lack of concept of operations (ConOps) and air traffic control tools to support safe and efficient Urban Air Mobility (UAM) operations with these new eVTOL aircraft (Kleinbekman et al., 2018).

Introducing electric propulsion systems into ground transportation seems to be relatively simple compared to the implementation in aviation. While ground based vehicles can easier cope with additional mass due to not fully developed electric storage and propulsion systems, aircraft are much more sensible to mass. Furthermore, typical trip distances as flown by aircraft are much larger that trips in ground vehicles (cars, buses, trains) and safety standards in aviation are extremely high. Finally, one must acknowledge the fact that current aircraft are already very efficient in terms of fuel burn per payload and distance. All these facts make it no easy task to develop electric propulsion system concepts for aviation, but it is of strong interest and necessary to determine the physical limitations of using electric energy for aircraft propulsion and to work out the requirements and guidelines for future development (Hepperle, 2012).

Range and payload of current electric aircraft is limited primarily due to low energy density of batteries. However, recent advances in battery technology promise storage of more than $1 \mathrm{kWh}$ of energy per kilogram of weight in the near future. This kind of energy storage makes possible the design of an electric aircraft comparable to, if not better than existing state-of-the art GA aircraft powered by internal combustion engines (Srilatha, 2012).

Although an electric aircraft powered only by batteries most capitalizes on the operating cost, noise and emissions benefits of electric propulsion, it also is most hampered by range limitations. Therefore, the electric propulsion designs considered herein use a hybrid architecture, in which shorter range missions can be completed solely on battery power, but a range extender is present for use for reserves or for longer-range missions, i.e. this paper does not deal with eVTOL PAVs and only focus on the sizing of a roadable PAVs to increase range and payload.

Low noise is essential to achieve community acceptance for PAVs. A significant portion of the Uber Elevate paper is devoted to defining a set of quantitative noise goals. They eventually select a target noise level of $62 \mathrm{dBA}$ (A-weighted decibels) with the vehicle hovering $500 \mathrm{ft}$ overhead. This is half the noise generated by a medium-size truck at $50 \mathrm{ft}$ and comparable to a Prius at $25 \mathrm{ft}$ (Brown and Harri, 2018). The development of unmanned aerial vehicles (UAVs) has attracted much attention in the aviation industry for decades. Pei-Hsiang Chung et al. presented the design, manufacturing and flight testing of an electric-powered experimental flying wing UAV (Chung et al., 2019). The design process starts with defining the performance requirements including the stall speed, maximal speed, cruise altitude, absolute ceiling and turn radius and speed. Gokcin developed a methodology for sizing the electric propulsion subsystems of UAVs (Gokcin et al., 2016). An electric-powered UAV is heavier than a petroleum UAV in all scenarios. A report from the US Department of Defense (DoD) addressed some significant technology needed for various UAVs (Cambone et al., 2005).

Sunlight is considered inexhaustible, and solar-powered UAVs can be in continuous flight in theory if they do not require maintenance. Therefore, many researchers have focused on solar-powered aircrafts. Brandt presented a methodology for the conceptual design of a solar-powered aircraft (Brandt and Gilliam, 1995).

Aircraft sizing is a critical aspect of a system-level study because it is a prerequisite for most design and analysis activities, including those related to the internal layout as well as cost and system effectiveness analyses (Lim et al., 2015; Raymer, 2018). For instance, one of the results of aircraft sizing, the initial estimation of the thrust or power required, is a primary input to any preliminary investigation of an engine company, particularly if a new propulsion system is jointly developed.

An optimization process is vital during the conceptual design process of an aircraft because an optimization process can enable the maximum aircraft performance by considering many 
different design variables (Shin et al., 2018). Among the variety of design variables currently used, an aerodynamic analysis for initial sizing is typically conducted with a surrogate modeling technique. In general, a surrogate model is used to retain the predictive capability of the design space while reducing the computational cost (Joo and Hwang, 2017).

Electric and hybrid propulsion systems have received a great deal of attention in recent years in various branches of transportation, including aviation. However, due to certain peculiar features of electric aircraft, requiring an analysis of design points not limited to those variables - basically empty and take-off weights, wing loading and power loading - is usually considered during the sizing of a traditionally propelled aircraft. The few electric aircraft currently existing clearly show a statistical correlation with regard to some key design parameters and design approaches starting with a statistical analysis of what has been done up to the present time. Subsequently, during the sizing procedure, procedures for nonelectric aircraft, including the analysis of the sizing matrix and the sizing of the aircraft weights, are intimately linked to the case of electric aircraft (Riboldi and Gualdoni, 2016).

The objective of this study is to design a roadable PAV that can be used on regular highways for ground-mode operations. Therefore, its dimensions are restricted to those allowed by highway regulations for safety and transportation. A computer program was also developed for the initial sizing of roadable PAVs considering their operability in Korea. Using this program, a roadable PAV concept that meets Korean road transportation regulations was designed. To enable road operations, a configuration with a folding wing was considered. Mission specifications were defined considering the conditions of the runways and roads in Korea. Driving range versus flying range largely depends on how far departure and arrival points are located from the airfield. In Korea, less than 20 airfields are available so that only flying range was considered in the mission profile. In the ground mode, road and parking regulations in Korea were considered to design a roadable PAV. Based on the defined mission specifications and engine types, constraint analyses were conducted to identify the optimal design points. Finally, the outcomes of the sizing process, in this case the maximum take-off weight (MTOW), thrust-to-weight (T/W) ratio, wing loading $(\mathrm{W} / \mathrm{S})$, power-to-weight $(\mathrm{P} / \mathrm{W})$ ratio, brake horsepower and fuel efficiency were analyzed and compared.

\section{Personal air vehicle concepts}

\section{Personal air vehicle configuration}

To select an airfoil for the main wing, airfoils in the University of Illinois Urbana-Champaign Airfoil Database (UIUC Airfoil Coordinates Database, 2019) were investigated. After comparing the lift-to-drag ratios, FX 63-137 was selected given that it has the highest lift-to-drag ratio. For a PAV, the larger the lift-to-drag ratios are, the more the fuel consumption can be reduced and the longer the distance the vehicle can travel, enabling more efficient flight.

To set the geometric constraints of the PAV configuration, the regulations pertaining to roads and parking lots in Korea were surveyed, as summarized in Tables 1-3 (Korea Law Translation Center, Parking Lot Act, 2019; Korea Ministry of Government Legislation, 2015).

The size of the main wing of the PAV was determined considering the widths of the roads and parking lots in Korea,
Table 1 Lane width regulation in Korea

\begin{tabular}{lccc}
\hline \multirow{2}{*}{ Type } & \multicolumn{3}{c}{ Minimum width of road (ft) } \\
& Local area & Urban area & Compact car road \\
\hline Highway & 11.5 & 11.5 & 10.7 \\
General road & & & \\
$\begin{array}{l}\text { Design speed (mph) } \\
\text { More than 50 }\end{array}$ & 11.5 & 10.7 & 10.7 \\
More than 43.5 & 10.7 & 10.7 & 9.8 \\
More than 37 & 10.7 & 9.8 & 9.8 \\
Under 37 & 9.8 & 9.8 & 9.8 \\
\hline
\end{tabular}

Table 2 Parking regulation in Korea (parallel parking type)

\begin{tabular}{lll}
\hline Type & Width (ft) & Length (ft) \\
\hline Compact & More than 5.6 & More than 14.8 \\
Standard & More than 6.6 & More than 19.7 \\
Roads in residential area & More than 6.6 & More than 16.4 \\
Two wheel vehicles only & More than 3.3 & More than 7.3 \\
\hline
\end{tabular}

Table 3 Parking regulation in Korea (other than parallel parking type)

\begin{tabular}{lll}
\hline Type & Width $(\mathrm{ft})$ & Length $(\mathrm{ft})$ \\
\hline Compact & More than 6.6 & More than 11.8 \\
Standard & More than 7.3 & More than 16.4 \\
Stretched & More than 8.2 & More than 16.7 \\
Handicapped only & More than 10.8 & More than 16.4 \\
Two wheel vehicles only & More than 3.3 & More than 7.3 \\
\hline
\end{tabular}

and a foldable wing structure was adopted for road operations and parking. For the sizing of the wing and tails, the wing geometries of the GA aircraft in Raymer (Shin et al., 2018) were consulted to set the aspect ratio, taper ratio and tail volume coefficients. A single slotted flap was selected to augment the lift during take-off and landing. A small black box was added to store flight data securely in case of accidents. The baseline PAV configuration is summarized in Table 4.

The engine that drives two axes was installed just behind the seat. One axis which passes tail boom is connected to the propeller which enables a flight. The other axis directly drive rear wheel which enable a road driving in ground mode.

Table 4 Roadable PAV configuration (baseline)

\begin{tabular}{ll}
\hline PAV Configuration (baseline) & \\
\hline PAV material & Composite \\
Wing airfoil & FX 63-137 \\
Trailing edge high lift device & Single slotted flap \\
Wing morphing & Folding-rotating \\
Propulsion type & Propeller \\
Propeller blade number & 3 \\
$\begin{array}{l}\text { Fuselage length/width/height } \\
\text { Main wing aspect ratio }\end{array}$ & $17 \mathrm{ft} / 6 \mathrm{ft} / 5 \mathrm{ft}$ \\
$\begin{array}{l}\text { Horizontal tail volume coefficient/aspect } \\
\text { ratio/taper ratio }\end{array}$ & 7.6 \\
$\begin{array}{l}\text { Vertical tail volume coefficient/aspect ratio/ } \\
\text { taper ratio }\end{array}$ & $0.7 / 3 / 0.5$ \\
\hline
\end{tabular}




\section{Personal air vehicle mission profile}

The mission profile was defined by setting the driving speed, driving distance, flying range, maximum speed, cruising speed, cruising altitude, diversion range, passengers, baggage, take-off ground roll, take-off altitude, rate of climb, stall speed and service ceiling. For sensitivity studies, a mission profile set was generated using a design of experiment (DOE) table.

DOE is an area of applied statistics that facilitates the design of an experiment and an analysis of the results. A DOE table simultaneously varies multiple design parameters and shows how those parameters affect the output.

The initial sizing efforts revealed that changing the take-off ground roll, cruise speed, rate of climb, stall speed, range and cruise altitude had greater effects compared to those of other mission parameters. To determine the minimum and maximum bounds of the parameters in the DOE table, the FAR PART 23 certification standard was considered. For example, the stall speed should not exceed $61 \mathrm{kt}$. The number of passengers, including the pilot, is limited to four. The geographic characteristics of Korea were also an important factor to consider. More than $70 \%$ of South Korea is mountainous, with the highest elevation being $6,282 \mathrm{ft}$ $(1,195 \mathrm{~m}$, Jiri Mountain), excluding Jeju Island. Therefore, the heights of the mountains must be considered when setting the cruising altitude. Existing runways for military or commercial aircraft are used. Current speed limits of cars are typically $37 \mathrm{mi} / \mathrm{h}$ in the city, $62 \mathrm{mi} / \mathrm{h}$ on national highways and $50 \mathrm{mi} / \mathrm{h}$ on local highways.

A set of 350 cases were generated using the lhsDesign function in MATLAB. Latin Hypercube Sampling (LHS) is a way of generating random samples of parameter values. It is widely used in Monte Carlo simulation because it can drastically reduce the number of runs necessary to achieve a reasonably accurate result. The lhsDesign function produced random numbers between 0 and 1 for the six mission variables. Then, the 350 cases were populated using the minimum and maximum bounds of the six variables and equation (1), as shown in Table 5. The maximum and minimum bounds of the variables were determined by referring existing roadable PAVs design variables, lengths and locations of airfields in Korea:

$$
\text { Min }+(\text { Max }- \text { Min }) * \text { Random number }
$$

\section{Personal air vehicle sizing process}

A roadable PAV sizing program was developed using Microsoft Excel and Visual Basic for Applications (VBA). The program consists of the mission, concepts, constraint analysis, aerodynamics, propulsion and weight analysis process.

To design a PAV using the PAV sizing program, the users select some of ideal tradeoff parameters (e.g. fuselage number and material; wing airfoil, configuration, material, folding mechanism and leading-trailing edge high-lift device; engine type; and landing gear) in the vehicle sizing process and the mission profiles. The user must then select one of two sizing options to run the sizing routine and obtain the sizing results. Option 1 selects the power and wing loading combination that minimizes the power required, and Option 2 selects the power and wing loading combination that minimizes the wing area. Figure 1 provides a flowchart of the PAV sizing program.

To size a PAV concept, the users input the airfoil and engine data into the program, select the configurations, set the mission and then start the sizing analysis.

The sizing process sets the initial weight estimate using the statistical weight equations of existing GA aircraft, performs aerodynamic and propulsion analyses using the input airfoil and engine data and then performs the constraint analysis. As the next step, the sizing process calculates the subsystem weights. Finally, the bisection method is used to converge to a final weight based on the initial weight estimate by repeating the constraint analysis (Nam, 2007). Figure 2 shows the sizing process of the PAV sizing program. Below, each step of the sizing process is described.

\section{Aerodynamic analysis}

The aerodynamics analysis process determines the geometry and aerodynamic coefficients of the aerodynamic surfaces, such as main wing, horizontal tail and vertical tail. The aerodynamic analysis results include the lift coefficient, angle of attack, drag coefficient and induced drag coefficients for the take-off, cruise and land mission segments.

For the aerodynamic analysis, various airfoil data, such as the lift curve slope $\left(C_{L \alpha}\right)$, lift coefficient at a zero angle of attack $\left(C_{L 0}\right)$ and maximum lift coefficient $\left(C_{L_{\max }}\right)$ were collected and used.

First, Oswald's span efficiency, e, is an important parameter that estimates the lift-induced drag of an aircraft, as shown in equation (4). Oswald's span efficiency was calculated using empirical equations for straight [equation (2)] and swept [equation (3)] wings (Gudmundsson, 2013):

$$
\begin{gathered}
e_{\text {straight wing }}=1.78 *\left(1-0.045 * A R^{0.68}\right)-0.64 \\
e_{\text {swept wing }}=4.61 *\left(1-0.045 * A R^{0.68}\right)\left(\cos \wedge_{L E}\right)^{0.15}-3.1
\end{gathered}
$$

\begin{tabular}{|c|c|c|c|c|c|c|}
\hline Case & TOFL (ft) & Cruise Speed (kt) & Rate of climb (fpm) & Stall speed (kt) & Flying range (nm) & Cruise altitude (ft) \\
\hline MIN & 1,100 & 70 & 300 & 43 & 150 & 6,000 \\
\hline MAX & 1,500 & 130 & 650 & 53 & 300 & 12,000 \\
\hline 1 & 1,239 & 123 & 644 & 51.5 & 262 & 10,904 \\
\hline 2 & 1,354 & 119 & 579 & 52.3 & 204 & 8,453 \\
\hline 3 & 1,388 & 86 & 609 & 52.5 & 254 & 10,365 \\
\hline 4 & 1,403 & 109 & 575 & 50.8 & 194 & 8,040 \\
\hline$\vdots$ & $\vdots$ & $\vdots$ & $\vdots$ & $\vdots$ & $\vdots$ & : \\
\hline 350 & 1,374 & 102 & 404 & 46.0 & 264 & 6,060 \\
\hline
\end{tabular}

Table 5 DOE design variables table 
Figure 1 PAV sizing program flow chart

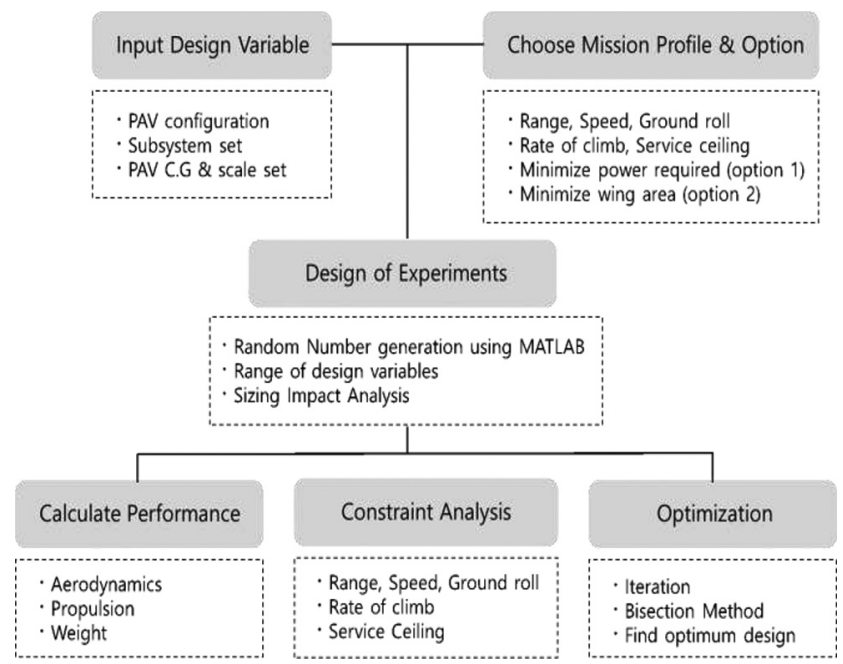

Figure 2 PAV sizing process

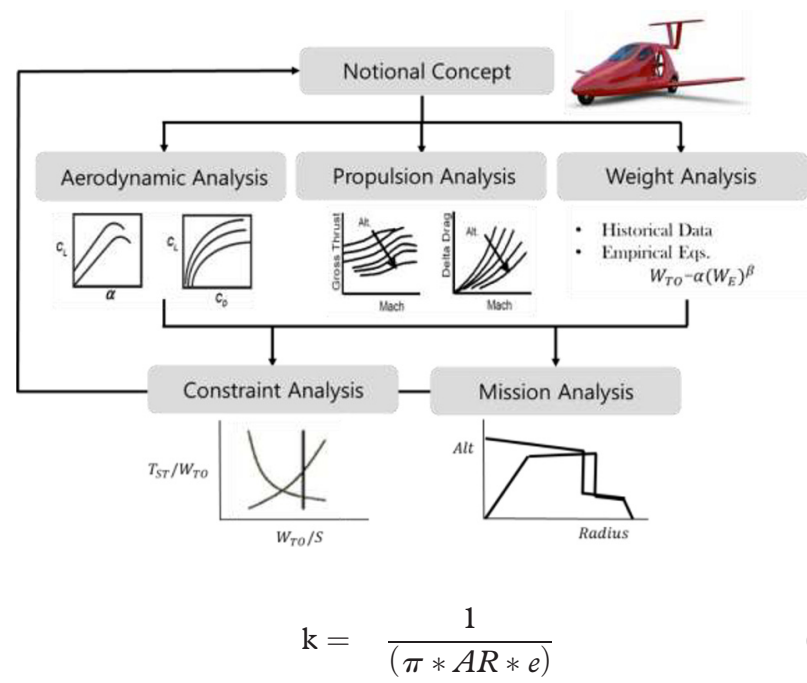

Here, $A R$ is the aspect ratio, $\wedge_{L E}$ is the leading edge sweep angle, and e is Oswald's span efficiency.

The lift and drag coefficients $\left(C_{L}, C_{D}\right)$ were then calculated using equations 5-11 (Gudmundsson, 2013). CLmax calculated using equation (7) will result in over-prediction so that other empirical approaches will provide more accurate CLmax:

$$
\begin{gathered}
C_{L \alpha}=\frac{2 * \pi * \mathrm{AR}}{\left(2+\sqrt{\left(\frac{A R * \beta}{k}\right)^{2} *\left(1+\frac{\tan ^{2} \wedge \frac{c}{2}}{\beta^{2}}\right)}+4\right)} \\
C_{L 0}=\left|\alpha_{Z L}\right| C_{L \alpha} \\
C_{L_{\max }}=\alpha_{Z L}+C_{L_{\alpha}} * \alpha_{C_{L_{\max }}} \\
\alpha_{C}=\left(\left(\frac{W}{Q * S}\right)-C_{L_{0}}\right)\left(\frac{1}{C_{L_{\alpha}}}\right)
\end{gathered}
$$

$$
C_{L}=\alpha_{Z L}+\alpha * C_{L_{\alpha}}
$$

In these equations, $C_{L \alpha}$ is the lift curve slope, $\beta$ is the Mach number parameter (Prandtl-Glauert), $\mathrm{k}$ is the ratio of the twodimensional lift curve slope to $2 \pi, \wedge_{c / 2}$ is the sweepback of the mid chord, $C_{L O}$ is the lift coefficient at a zero angle of attack, $\alpha_{Z L}$ is the zero lift angle of attack, $\alpha_{C_{L_{\max }}}$ is the maximum lift coefficient angle of attack, and $\alpha_{C}$ is the cruise angle of attack:

$$
\begin{gathered}
C_{D_{\min }}=\text { airfoil } C_{D_{\min }}+\text { High lift device } \Delta C_{d} \\
C_{D}=C_{D_{0}}+k * C_{L}^{2}
\end{gathered}
$$

Here, $C_{D_{0}}$ is the drag coefficient at a zero angle of attack.

The definition of the drag coefficient in equation (11) accounts for only the wing contribution. The total PAV drag polar can also be expressed in the form of equation (11).

\section{Propulsion analysis}

The propulsion process calculates the performance of the propulsion system, the generator, the electric motor and the propeller for the take-off, climb, cruise and descent mission phases.

The propulsion analysis is performed using the regression equations that were fitted using existing engine data as summarized in Table 6. Figure 3 shows the weight and engine horsepower relationship for gasoline engines, diesel engines and electric motors. Equations (12)-(14) that are created using linear fit of the data estimate engine weights for different propulsion types as a function of required horsepower.

$$
\begin{aligned}
& \text { Gasoline Engine Weight }=1.38 * \mathrm{HP}+39.81 \\
& \text { Diesel Engine Weight }=1.07 * \mathrm{HP}+185.85
\end{aligned}
$$

ElectricEngineWeight $=0.0027 * \mathrm{HP}^{2}+0.5951$

$$
* \mathrm{HP}+1.1328
$$

When designing a propeller-driven aircraft, the diameter of the propeller is an important design parameter that impacts various characteristics of the aircraft, such as noise and geometric constraints. Therefore, the following equation is used to calculate the diameter of the propeller (Gudmundsson, 2013).

For two-bladed propellers:

$$
D_{2-\text { blade }}=10000 * \sqrt[4]{\frac{P_{B H P}}{53.5 * R P M^{2} * V_{T A S}}}
$$

For four-bladed propellers:

$$
D_{4-\text { blade }}=10000 * \sqrt[4]{\frac{P_{B H P}}{111 * R P M^{2} * V_{T A S}}}
$$

The average of equations 15 and 16 is used for three-bladed propellers:

$$
\begin{aligned}
D_{3 \text {-blade }} & =\frac{D_{2 \text {-blade }}+D_{4-\text { blade }}}{2} \\
& =10000 * \sqrt[4]{\frac{P_{B H P}}{75.8 * R P M^{2} * V_{T A S}}}
\end{aligned}
$$


Table 6 DOE design variables table

\begin{tabular}{|c|c|c|c|c|c|}
\hline \multicolumn{3}{|c|}{ Gasoline engine } & \multicolumn{3}{|c|}{ Diesel engine } \\
\hline Model & HP@RPM & Weight(lb) & Model & HP@RPM & Weight(lb) \\
\hline 912 ULS DCDI & $100 @ 5800$ & 140 & SR305-230E & $227 @ 2200$ & 455 \\
\hline 912 IS/ISC SPORT & $100 @ 5800$ & 140 & AE300-E4 & 168@2300 & 410 \\
\hline $0-200-A, B$ & $100 @ 2750$ & 224 & Centurion 2.0 & $135 @ 3890$ & 295 \\
\hline 914 UL/F & 115@5800 & 140 & : & $\vdots$ & $\vdots$ \\
\hline 914 UL DCDI & $115 @ 5800$ & 166 & & & \\
\hline $0-235-L 2 A$ & $118 @ 2800$ & 222 & & Electric engine & \\
\hline $10-240-A, b$ & 125@2800 & 246 & Model & KW@HP & Weight(lb) \\
\hline \multirow{4}{*}{$\begin{array}{l}0-320-H 2 A D \\
\vdots\end{array}$} & $160 @ 2700$ & 253 & Yuneec 10 & 10@13 & 9.9 \\
\hline & $\vdots$ & $\vdots$ & Yuneec 20 & 20@27 & 18.1 \\
\hline & & & Yuneec 40 & 40@54 & 42 \\
\hline & & & Yuneec 60 & $60 @ 80$ & 66 \\
\hline
\end{tabular}

Figure 3 Engine regression graph
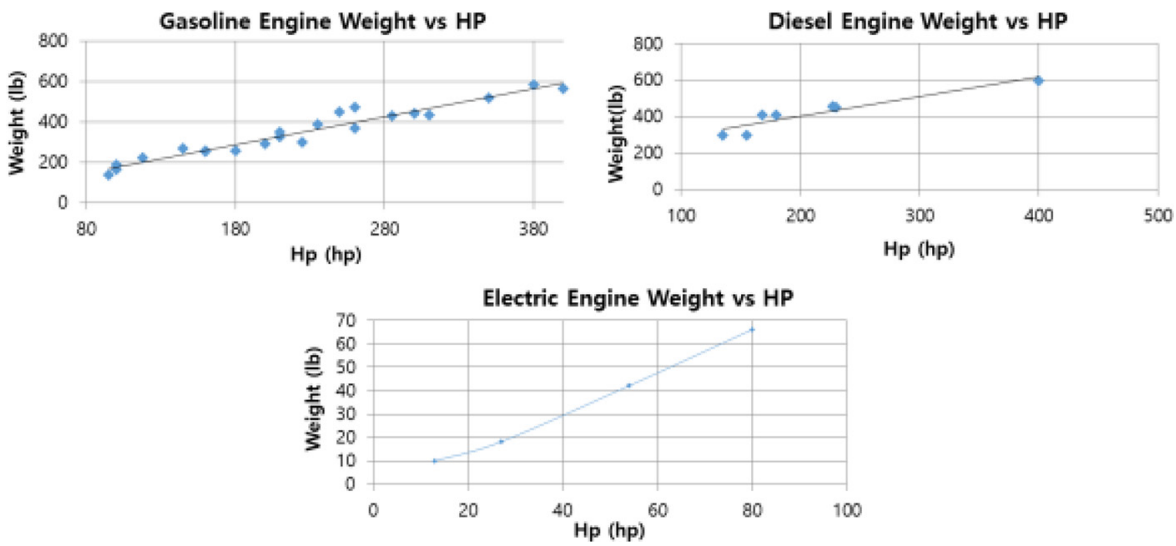

where $\mathrm{D}$ is the diameter of the propeller, $P_{B H P}$ is the brake horsepower, RPM denotes the revolutions per minute of the propeller, and $V_{T A S}$ is the airspeed.

The pitch angle of the propeller is typically determined following the recommendations of propeller manufacturers. The following estimation is used in the sizing process:

$$
P_{D}=1251.36\left(\frac{V_{K T A S}}{R P M}\right)\left(\frac{1}{\eta_{p}}\right)
$$

where $P_{D}$ is the pitch angle of the propeller.

The thrust from the propeller is then calculated as follows:

$$
T=\frac{\eta_{p} P}{V}=\frac{\eta_{p} * 550 * P_{B H P}}{V}
$$

The new propeller efficiency is then calculated as follows using bisection method:

$$
\begin{gathered}
V_{\text {induced }}=0.5 * \sqrt{\frac{V_{T A S}^{2}+2 * T}{\rho * \frac{\pi * P_{\text {rop }}^{2} \text { diameter }}{4}}}-V_{T A S} \\
\eta_{\text {ideal }}=\frac{1}{1+\frac{V_{\text {induced }}}{V_{T A S}}}
\end{gathered}
$$

$$
\begin{gathered}
\eta_{\text {new }}=\text { Viscous } * \eta_{\text {ideal }} \\
\text { Delta }=\operatorname{Abs}\left(\eta_{p}-\eta_{\text {new }}\right)<0.0001 \\
\eta_{\text {new }}=\eta_{p}
\end{gathered}
$$

where $V_{\text {induced }}$ is the induced velocity, $\eta_{\text {ideal }}$ is the ideal efficiency, $\eta_{\text {new }}$ is the new propeller efficiency, and Delta is the difference of propeller efficiency.

\section{Weight analysis}

During the process of the weight analysis, weight estimates are iteratively calculated. During the weight analysis, the subsystem weights are calculated using equations 25-36 (Gudmundsson, 2013):

$$
\begin{aligned}
W_{W}= & 0.036 * S_{W}^{0.758} * W_{F W}^{0.0035} *\left(\frac{A R_{W}}{\cos ^{2} \wedge_{C / 4}}\right)^{0.6} * q^{0.006} * \lambda^{0.04} \\
& *\left(\frac{100 * t / c}{\cos \wedge_{C / 4}}\right)^{-0.3}\left(n_{z} W_{o}\right)^{0.49}
\end{aligned}
$$

where $W_{W}$ is the predicted weight of the wing in $\mathrm{lbf}, S_{W}$ is the trapezoidal wing area in $f t^{2}, W_{F W}$ is the weight of fuel in the 
wing in lbf, $\wedge_{c / 4}$ is the wing sweep at $25 \%$ MGC, $\lambda$ is the wing taper ratio, $n_{z}$ is the ultimate load factor, and $W_{0}$ is the design gross weight in lbf:

$$
\begin{aligned}
W_{H T}= & 0.016 *\left(n_{z} W_{o}\right)^{0.414} * q^{0.168} * S_{H T}^{0.896}\left(\frac{100 * \frac{t}{c}}{\cos \wedge_{H T}}\right)^{-0.12} \\
& *\left(\frac{A R_{H T}}{\cos ^{2} \wedge_{H T}}\right)^{0.043} * \lambda_{H T}^{-0.02}
\end{aligned}
$$

where $W_{H T}$ is the predicted weight of $\mathrm{HT}$ in lbf, $S_{H T}$ is the trapezoidal HT area in $f t^{2}, \wedge_{H T}$ is the HT sweep at $25 \% \mathrm{MGC}$, and $\lambda_{H T}$ is the HT taper ratio:

$$
\begin{aligned}
W_{V T}= & 0.073 *\left(1+0.2 F_{\text {tail }}\right) *\left(n_{z} W_{o}\right)^{0.376} * q^{0.122} \\
& * S_{V T}^{0.873}\left(\frac{100 * \frac{t}{c}}{\cos \wedge_{V T}}\right)^{-0.49} *\left(\frac{A R_{V T}}{\cos ^{2} \wedge_{V T}}\right)^{0.357} * \lambda_{V T}^{0.039}
\end{aligned}
$$

where $W_{V T}$ is the predicted weight of VT in lbf, $F_{\text {tail }}$ is 0 for a conventional tail and 1 for a T-tail, $S_{V T}$ is the trapezoidal VT area in $f t^{2}, \wedge_{V T}$ is the VT sweep at $25 \%$ MGC, and $\lambda_{V T}$ is the VT taper ratio:

$$
\begin{aligned}
W_{F}= & 0.052 * S_{F U S}^{1.086} *\left(n_{z} W_{o}\right)^{0.177} * l_{H T}^{-0.051}\left(\frac{l_{F S}}{d_{F S}}\right)^{-0.072} \\
& * q^{0.241}+11.9 *\left(V_{P} \Delta P\right)^{0.271}
\end{aligned}
$$

where $W_{F}$ is the predicted weight of the fuselage in lbf, $S_{F U S}$ is the fuselage wetted area in $f t^{2}, l_{F S}$ is the length of the fuselage structure in $\mathrm{ft}, d_{F S}$ is the depth of the fuselage structure in $\mathrm{ft}, V_{P}$ is the volume of the pressurized cabin section in $\mathrm{ft} 3$, and $\Delta P$ is the cabin pressure differential:

$$
W_{M L G}=0.095 *\left(n_{l} W_{l}\right)^{0.768} *\left(\frac{L_{m}}{12}\right)^{0.409}
$$

where $W_{M L G}$ is the predicted weight of the main landing gear in lbf, $n_{l}$ is the ultimate landing load factor, $W_{l}$ is the design landing weight in $\mathrm{lbf}$, and $L_{m}$ is the length of the main landing gear strut in inches:

$$
W_{N L G}=0.125 *\left(n_{l} W_{l}\right)^{0.566} *\left(\frac{L_{n}}{12}\right)^{0.845}
$$

where $\mathrm{W}_{N L G}$ is the predicted weight of the nose landing gear in lbf, $n_{l}$ is the ultimate landing load factor, $W_{l}$ is the design landing weight in lbf, and $L_{n}$ is the length of the nose landing gear strut in inches:

$$
W_{E I}=2.575 * W_{E N G}^{0.922} N_{E N G}
$$

where $W_{E I}$ is the predicted weight of the installed engine in lbf, $W_{E N G}$ is the uninstalled engine weight in lbf, and $N_{E N G}$ is the number of engines:

$$
W_{F S}=2.49 * Q_{t o t}^{0.726} *\left(\frac{Q_{t o t}}{Q_{t o t}+Q_{i n t}}\right)^{0.363} * N_{T A N K}^{0.242} N_{E N G}^{0.157}
$$

where $W_{F S}$ is the predicted weight of the fuel system in lbf, $Q_{t o t}$ is the total fuel quantity in gallons, $Q_{i n t}$ is the fuel quantity in integral fuel tanks in gallons, and $N_{\text {TANK }}$ is the number of fuel tanks:

$$
W_{C T R L}=0.053 * l_{F S}^{1.536} * b^{0.371} *\left(n_{z} * W_{O} * 10^{-4}\right)^{0.80}
$$

where $W_{C T R L}$ is the predicted weight of the flight control system in $\mathrm{lbf}$ and $\mathrm{b}$ is the wingspan in $\mathrm{ft}$ :

$$
W_{A V}=2.117 * W_{U A V}^{0.993}
$$

where $W_{A V}$ is the predicted weight of the avionics installation system in lbf and $W_{U A V}$ is the predicted weight of the uninstalled avionics in lbf:

$$
W_{E L}=12.57 *\left(W_{F S}+W_{A V}\right)^{0.51}
$$

where $W_{E L}$ is the predicted weight of the electrical system in lbf:

$$
W_{F U R N}=0.0582 * W_{O}-65
$$

where $W_{F U R N}$ is the predicted weight of the furnishings in lbf and $W_{O}$ is the maximum take-off weight in lbf.

These weight relationships were derived using the statistical data of existing conventional fixed-wing GA aircrafts. Although roadable PAV is not a conventional fixed-wing GA configuration, available roadable PAV weight data was not enough to derive statistical weight estimation equations so that a conventional fixed-wing GA aircraft weight estimation equation was used in this research. Instead, weight of a folding mechanism was added for a roadable PAV.

\section{Folding mechanism}

Because a roadable PAV should be compatible with both air and road operations, a folding wing was adopted. The wing folding mechanism is widely used to store and transport naval aircraft in an aircraft carrier. For fixed-wing roadable PAVs, the maximum width of the aircraft should be less than the width of the traffic lanes for the ground mode. However, one of the drawbacks of the folding mechanism is an increase in the weight. Therefore, an accurate estimation of the weight increase is important during the conceptual design.

The most common folding mechanism is the simple folding type, which has the wing rotate with respect to the folding axis on top of the wing surface. Simple folding enables a simple structure, which is easier to manufacture. The weight penalty is also relatively small. The weight of the wing increases due to the installation of a butt joint, and the weight increase can be calculated using the following equations (Yarygina and Popov, 2012):

$$
\begin{gathered}
\bar{m}_{w}^{\text {fold }}=\bar{m}_{w}^{\text {nonfold }}\left(1+\Delta \bar{m}_{\text {fold }}\right) \\
\Delta \bar{m}_{\text {fold }}=\bar{m}_{\text {fold }}^{\text {ins }}+\bar{m}_{\text {fold }}^{\text {mech }}+\bar{m}_{\text {pin }}^{\text {mech }} \\
\bar{m}_{w}^{\text {fold }}=\bar{m}_{w}^{\text {nonfold }}\left(1+\bar{m}_{\text {fold }}^{\text {ins }}+\bar{m}_{\text {fold }}^{\text {mech }}+\bar{m}_{\text {pin }}^{\text {mech }}\right)
\end{gathered}
$$

where $\bar{m}_{w}^{\text {fold }}$ is the total weight of a folding wing, $\bar{m}_{w}^{\text {nonfold }}$ is the weight of the non-folding wing, $\bar{m}_{\text {fold }}^{\text {ins }}$ is the weight of any 
inserted structures, $\bar{m}_{\text {fold }}^{\text {mech }}$ is the folding mechanism weight, and $\bar{m}_{\text {pin }}^{\text {mech }}$ is the pin weight.

The weight of the folding wing can vary significantly depending on the spanwise location of the folding axis. For simple folding, the average weight increases at three spanwise folding locations are summarized in Table 7 based on existing data. Due to the lack of existing data in the literature, the weight increases for the folding/rating and telescoping types were determined assuming that the mechanism of the folding/ rotating system would be heavier than the weight of the simple folding type. Subsequently, a telescoping system was assumed to be heavier than a folding/rotating system. The weight increases of the three different folding systems applied to the roadable PAV design in this study are summarized in Table 7.

\section{Constraint analysis}

As shown in Figure 4, the constraint analysis process uses the input from the mission, concepts and aerodynamics data to calculate and compare the T/W ratio, W/S ratio, $\mathrm{P} / \mathrm{W}$ ratio and brake horsepower to find the optimal design point for the PAV. During the mission process, the estimated weights and sizing results for the sized PAV are based on the mission profiles defined by the user. In conceptual process, the input

Table 7 Weight increases for folding mechanisms

\begin{tabular}{|c|c|c|}
\hline $\begin{array}{l}\text { Folding position } \\
\text { (spanwise } \\
\text { position } \\
\text { percentage) }\end{array}$ & $\begin{array}{l}\text { Simple folding }(\triangle \mathrm{m}) \\
\text { (weight increase } \\
\text { percentage compared } \\
\text { to without folding) }\end{array}$ & $\begin{array}{c}\text { Folding/rotating }(\triangle \mathrm{m}) \\
\text { (Folding mechanism weight } \\
\text { increase percentage } \\
\text { compared to Rotating } \\
\text { mechanism) }\end{array}$ \\
\hline 0.64 & 0.18 & 0.2 \\
\hline 0.48 & 0.21 & 0.25 \\
\hline 0.32 & 0.39 & 0.41 \\
\hline
\end{tabular}

-Figure 4 Constraint analysis process

\section{xmlXPathCompOpEval: parameter error xmlXPathEval: evaluation failed}

parameters are populated to define the PAV configurations by selecting the values for the parameters listed in Table 8 .

One of the key steps in relation to aircraft sizing is to determine the optimal T/W ratio and W/S ratio. T/W has a direct impact on the ground roll distance, rate of climb, cruise speed and height of the service ceiling. With a higher $\mathrm{T} / \mathrm{W}$, the aircraft can accelerate and climb more rapidly, cruise at higher speeds and maintain a higher turn rate. T/W is calculated using equations $40-43$ for each of the performance requirements considered:

$$
\begin{gathered}
\left(\frac{T}{W}\right)_{\text {Ground Roll }}=\frac{V_{L O F}^{2}}{2 g \cdot S_{G}}+\frac{q \cdot C_{D} T O}{W / S}+\mu\left(1-\frac{q \cdot C_{D} T O}{W / S}\right) \\
\left(\frac{T}{W}\right)_{\text {Rate of Climb }}=\frac{V_{V}}{V}+\frac{q}{(W / S)} C_{D \text { min }}+\frac{k}{q} \cdot\left(\frac{W}{S}\right) \\
\left(\frac{T}{W}\right)_{\text {Cruise }}=q \frac{C_{D} \min }{(W / S)}+k\left(\frac{1}{q}\right)\left(\frac{W}{S}\right) \\
\left(\frac{T}{W}\right)_{\text {Service Ceiling }}=\frac{V_{V}}{\sqrt{\frac{2}{\rho}\left(\frac{W}{S}\right) \sqrt{\frac{k}{3 \cdot C_{D} \text { min }}}}}+4 \sqrt{\frac{k \cdot C_{D} \text { min }}{3}}
\end{gathered}
$$

\begin{tabular}{|c|c|c|c|}
\hline \multicolumn{4}{|c|}{ Vehicle general configuration } \\
\hline \multirow[t]{3}{*}{ Fuselage } & Fuselage number & Empennage & Vertical tail airfoil \\
\hline & Material & & Vertical tail configuration \\
\hline & Cabin configuration & & Vertical tail folding \\
\hline \multirow[t]{10}{*}{ Lift generation } & Wing airfoil & & Vertical tail fold number \\
\hline & Wing configuration & & Horizontal tail airfoil \\
\hline & Wing sweep & & Horizontal tail configuration \\
\hline & Wing shape & & Horizontal tail folding \\
\hline & Wing material & & Horizontal tail fold number \\
\hline & Winglet type & Propulsion system & Propulsion system architecture \\
\hline & Leading edge high lift device & & Main engine type \\
\hline & Trailing edge high lift device & & Main engine generator \\
\hline & Wing folding & & Main engine turbocharged \\
\hline & Wing fold number & & Distributed propulsion \\
\hline \multirow[t]{2}{*}{ Additional car engine } & Car engine number & & Propulsion engine number \\
\hline & Car engine type & & Propulsion engine type \\
\hline \multirow[t]{2}{*}{ Propulsion } & Propeller system & & Propulsion engine turbocharged \\
\hline & Propeller blades & & Propulsion configuration \\
\hline \multirow[t]{3}{*}{ Energy storage } & Energy type & Miscellaneous & Air con and Anti icing \\
\hline & Backup/boost battery & & Ballistic parachute \\
\hline & Regenerative turbine & & Roadable \\
\hline Landing gear & Landing gear configuration & & \\
\hline
\end{tabular}

Here, $C_{L T O}$ is the lift coefficient during the take-off run, $C_{D T O}$ is the drag coefficient during the take-off run, $\mathrm{q}$ is the dynamic

Table 8 Roadable PAV configuration design parameters 
pressure at $V_{L O F} / \sqrt{2}$ and the selected altitude, $S_{G}$ is the ground run, $V_{L O F}$ is the liftoff speed, $\mu$ is the ground friction constant, $\mathrm{g}$ is the acceleration due to gravity, $\mathrm{V}$ is the airspeed, $V_{V}$ is the vertical speed, $C_{D \text { min }}$ is the minimum drag coefficient, and k is the lift-induced drag constant.

$\mathrm{W} / \mathrm{S}$ is used to determine the relative size of the wing during the sizing process. A lower W/S is desirable to ensure adequate aerodynamic lift at low speeds. W/S was calculated using equation (44):

$$
\frac{W}{S}=\frac{1}{2} \rho V_{\text {stall }}^{2} C_{L_{\max }}
$$

where $V_{\text {stall }}$ is the stall speed and $C_{L \max }$ is the maximum lift coefficient.

$\mathrm{P} / \mathrm{W}$ was calculated using equation (45). Typical T/W, W/S and $\mathrm{P} / \mathrm{W}$ values for various aircraft types are set as shown in Table 9 (Raymer, 2018; Gudmundsson, 2013):

$$
\frac{P}{W}=\frac{(T / W) V}{\left(550 * \eta_{p}\right)}
$$

The optimal design point of a PAV can be obtained from these conditions and the bisection method, as shown in Figure 5.

\section{Bisection method}

\section{Bisection method}

During the process of the constraint analysis, the bisection method is used for optimization. The bisection method finds a solution by repeatedly dividing an interval into two equal subintervals and identifying the subinterval in which a solution must exist. This algorithm sets the intervals, assuming the existence of a solution, such that it is suitable when the function is simple, and the main purpose is to find the root of the function. The bisection method is used to optimize the PAV weight.

Table 9 Typical thrust to weight, wing loading, horsepower to weight value for a roadable PAV

\begin{tabular}{lc}
\hline Variables & Value \\
\hline Thrust to weight $(\mathrm{T} / \mathrm{W}, \mathrm{lb} / \mathrm{lb})$ & 0.22 \\
Wing loading $\left(\mathrm{W} / \mathrm{S}, \mathrm{lb} / \mathrm{ft}^{2}\right)$ & 17 \\
Horsepower to weight $(\mathrm{P} / \mathrm{W}, \mathrm{hp} / \mathrm{lb})$ & 0.06 \\
\hline
\end{tabular}

For an interval $[a, b]$, if a function $f$ is continuous and if $\mathrm{f}(\mathrm{a}) \mathrm{f}(\mathrm{b})<0$, a root that satisfies $\mathrm{f}(\mathrm{x})=0$ must exist in $[\mathrm{a}, \mathrm{b}]$. Then, new intervals using $\frac{|b-a|}{2}$ as the new bounds are created and tested for the existence of a root. After repeating the process $n$ times, the interval converges to the root $x$ that satisfies $f(x)=0$ (Burden and Faires, 2011).

\section{Optimal design point}

We set the statistical figure of the existing GA class aircraft to the initial weight, as shown in Table 10 and perform the constraint analysis using the bisection method:

$$
\begin{gathered}
\text { if, }\left|\frac{W_{i+1}-W_{i}}{W_{i+1}}\right|>0.000001 \\
W_{i}=0.5 \times\left(W_{i+1}+W_{i}\right) \\
W_{i+1}=W_{i}
\end{gathered}
$$

Here, $W_{i+1}$ is the weight after the iterative process and $W_{i}$ is calculated as in equation (47). The repetition process is carried out until the conditions in equation (46) are met, and the final value of $W_{i+1}$ is derived.

As shown in Table 10, the first weight estimate result was similar to the existing GA aircraft weights (CESSNA 152, 2019; DIAMOND DA20, 2019).

We locate the optimal design point, as shown in Figure 5, through the weight derived after three additional rounds of these iterations. Margins from the constraint analyses were not considered in this research although it should be maintained because the analyses that led to the identification of constraint curves is affected by inevitable uncertainty.

Table 10 Initial weight assumption values (general aviation)

\begin{tabular}{lrrr}
\hline & $\begin{array}{c}\text { First } \\
\text { estimate }\end{array}$ & $\begin{array}{c}\text { Cessna } \\
152\end{array}$ & $\begin{array}{c}\text { Diamond } \\
\text { DA 20 }\end{array}$ \\
\hline Maximum take-off weight & $1,648 \mathrm{lb}$ & $1,670 \mathrm{lb}$ & $1,609 \mathrm{lb}$ \\
Empty weight & $950 \mathrm{lb}$ & $1081 \mathrm{lb}$ & $1145 \mathrm{lb}$ \\
Crew weight & $170 \mathrm{lb}$ & $186 \mathrm{lb}$ & $148 \mathrm{lb}$ \\
Fuel weight & $308 \mathrm{lb}$ & $217 \mathrm{lb}$ & $168 \mathrm{lb}$ \\
Payload weight & $220 \mathrm{lb}$ & $186 \mathrm{lb}$ & $148 \mathrm{lb}$ \\
Useful load weight & $698 \mathrm{lb}$ & $589 \mathrm{lb}$ & $464 \mathrm{lb}$ \\
\hline
\end{tabular}

Figure 5 Constraint analysis wing loading vs. power to weight, wing loading vs thrust to weight
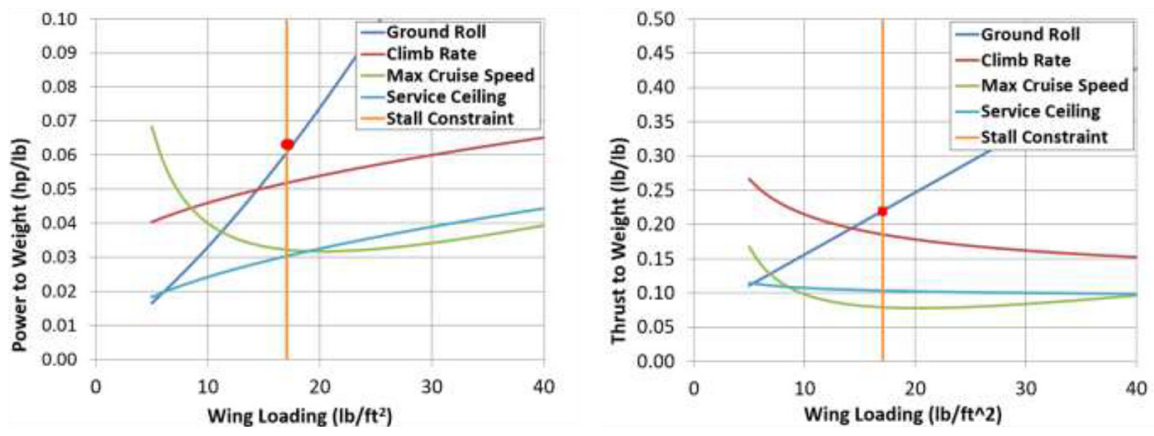


\section{Personal air vehicle sizing}

\section{Personal air vehicle sizing analysis}

For each of the cases in the DOE table, a roadable PAV was sized for four different propulsion types: a gasoline engine, diesel engine, gasoline hybrid engine and diesel hybrid engine. In this study, serial hybrid engines were used because of the simplicity compared to parallel hybrid engine. The advantage of serial hybrid engine is that there is no mechanical link between the combustion engine and the wheels. The enginegenerator group can be located everywhere. The serial hybrid engine has no conventional mechanical transmission elements (gearbox, transmission shafts). Separate electric wheel motors can be implemented easily. The combustion engine can operate in a narrow rpm range (its most efficient range), even as the car changes speed. However, serial hybrid engines have weaknesses of increasing total weight, cost and size of the powertrain because the internal combustion engine, the generator and the electric motor are dimensioned to handle the full power of the vehicle. The power from the combustion engine has to run through both the generator and electric motor. During long-distance highway driving, the total efficiency is inferior to a conventional transmission because of the several energy conversions.

Variables affecting the selected engine type are summarized in Table 11.

Table 12 provides the minimum and maximum values of the MTOW, wing area, wing span, engine power and fuel efficiency of the 350 sizing results using the DOE table for each engine type.

Next, the sizing results that were suitable for a roadable PAV were selected from the 350 cases. For example, the roadable PAV should allow for road operation and parking. Accordingly, the sizing results with wing spans of less than $40 \mathrm{ft}$ were selected. To meet the FAR PART 23 certification requirement, the MTOW was limited to $6,000 \mathrm{lb}$. In addition, considering

Table 11 Variables affecting the selected engine type

\begin{tabular}{|c|c|c|c|c|}
\hline & Gasoline & Diesel & $\begin{array}{l}\text { Gasoline } \\
\text { hybrid }\end{array}$ & $\begin{array}{l}\text { Diesel } \\
\text { hybrid }\end{array}$ \\
\hline $\begin{array}{l}\text { Propulsion system } \\
\text { architecture }\end{array}$ & Gas only & Gas only & $\begin{array}{l}\text { Hybrid } \\
\text { electric serial }\end{array}$ & $\begin{array}{l}\text { Hybrid } \\
\text { electric serial }\end{array}$ \\
\hline Main engine & - & - & IC-Avgas & IC-Diesel \\
\hline $\begin{array}{l}\text { Main engine } \\
\text { generator }\end{array}$ & - & - & True & True \\
\hline $\begin{array}{l}\text { Propulsion engine } \\
\text { type }\end{array}$ & IC-Avgas & IC-Diesel & Electric & Electric \\
\hline $\begin{array}{l}\text { Backup/boost } \\
\text { battery }\end{array}$ & - & - & True & True \\
\hline
\end{tabular}

the typical values of existing GA aircraft, the range of $\mathrm{P} / \mathrm{W}$ used was from 0.06 to 0.08 , and the range of W/S was from between 16 and 18. Among the design variables, changes in the stall speed had the greatest impact on the sizing results. Designs with stall speeds between 45.3 and $49 \mathrm{kt}$ were selected. Stall speeds of less than $45.3 \mathrm{kt}$ or greater than $49 \mathrm{kt}$ caused $\mathrm{P} / \mathrm{W}$ and W/S to exceed the selected boundaries. For the other design variables, the sizing converged to the appropriate bounds for all ranges set by the DOE. Some performances of the optimized sizing results for various engine types that are obtained based on DOE are given in Figures 6, 7 and 8.

The minimum MTOW cases from Figure 7 and the maximum fuel efficiency cases from Figure 8 are summarized in Table 13.

As indicated by the minimum MTOW cases, the wing area, wing span and required engine power increased with an increase in the MTOW. However, because the fuel efficiency influenced not only the MTOW but also the flight distance, Case 39 had a higher MTOW than Case 313 despite the better fuel efficiency. For similar reasons, Case 207, a case with maximum fuel efficiency, had better fuel efficiency than Case 152 despite the higher MTOW.

For each of the four engine types, the sizing results with the lowest MTOW were selected as the optimal sizing cases, as summarized in Table 14. The four optimal designs in the table have similar W/S and P/W values. However, their MTOWs, wing areas, and fuel efficiency rates differ significantly due to the differences in the propulsion system weights.

Unlike automobiles, PAVs with hybrid gasoline or hybrid diesel engines showed worse fuel efficiency outcomes than PAVs with internal combustion (IC) engines due to the weight increase caused by the additional electric propulsion system. For a roadable PAV or fixed-wing aircraft, the power required

Figure 6 P/W vs W/S sizing result for different kinds of engines
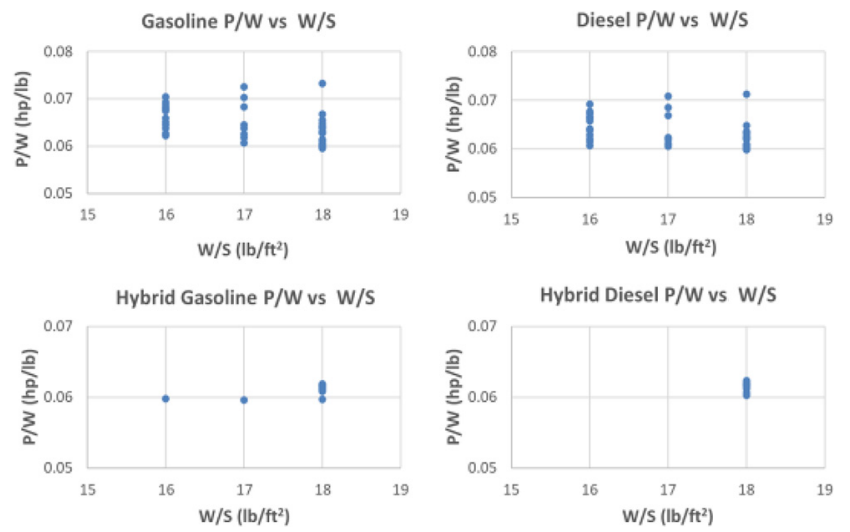

Table 12 Roadable PAV sizing result (min/max)

\begin{tabular}{|c|c|c|c|c|c|c|c|c|}
\hline & \multicolumn{2}{|c|}{ Gasoline } & \multicolumn{2}{|c|}{ Diesel } & \multicolumn{2}{|c|}{ Hybrid gasoline } & \multicolumn{2}{|c|}{ Hybrid diesel } \\
\hline & Min & Max & Min & Max & Min & Max & Min & Max \\
\hline MTOW (lb) & 1,999 & 2,811 & 2,192 & 2,917 & 2,447 & 4,189 & 2,716 & 4,254 \\
\hline Wing area $\left(f t^{2}\right)$ & 95 & 188 & 103 & 196 & 118 & 276 & 130 & 281 \\
\hline Wing span (ft) & 27 & 38 & 28 & 39 & 30 & 46 & 31 & 46 \\
\hline Eng power(BHP) & 91 & 197 & 99 & 200 & 127 & 301 & 142 & 305 \\
\hline Fuel efficiency (mpg) & 7.41 & 13.29 & 7.76 & 13.79 & 5.71 & 11.40 & 5.92 & 11.60 \\
\hline
\end{tabular}


Figure 7 Maximum takeoff weight sizing result

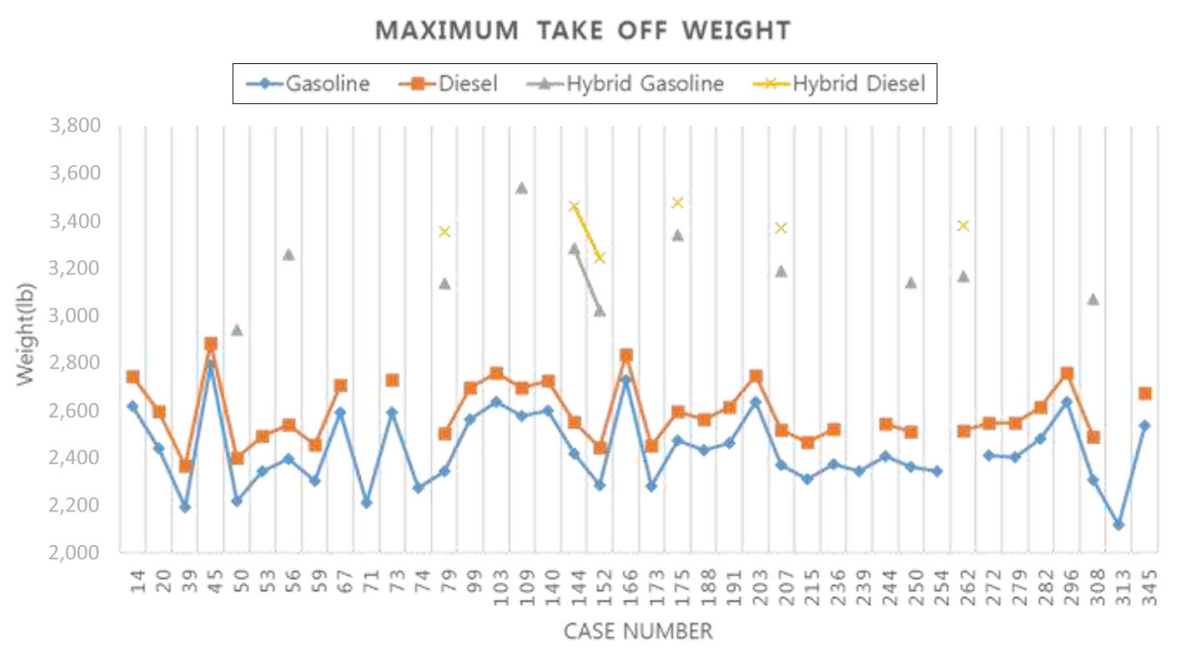

Figure 8 Fuel efficiency sizing result

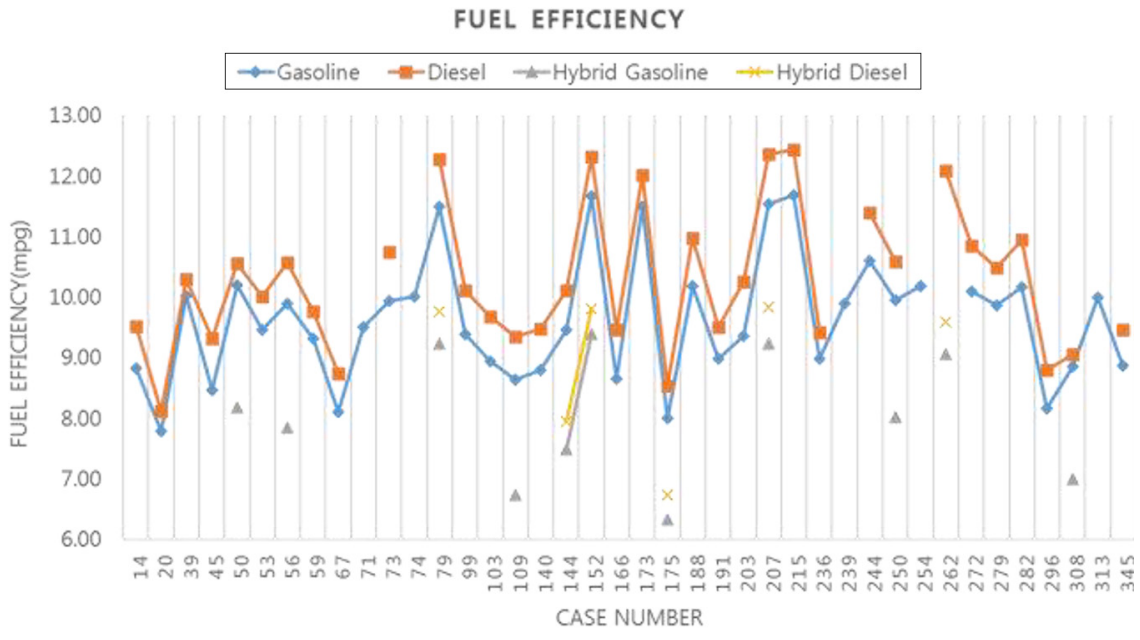

Table 13 Sizing result for MTOW and fuel efficiency

\begin{tabular}{|c|c|c|c|c|c|c|c|c|}
\hline Case no. & $\begin{array}{l}\text { MTOW } \\
\text { (lb) }\end{array}$ & $\begin{array}{c}\text { Wing } \\
\text { area }\left(f t^{2}\right)\end{array}$ & Wing span (ft) & $\mathrm{T} / \mathrm{W}(\mathrm{lb} / \mathrm{lb})$ & $\mathrm{W} / \mathrm{S}\left(\mathrm{lb} / \mathrm{ft}^{2}\right)$ & $\mathrm{P} / \mathrm{W}$ (hp/lb) & $\begin{array}{c}\text { Engine power } \\
\text { (BHP) }\end{array}$ & $\begin{array}{l}\text { Fuel efficiency } \\
\text { (mpg) }\end{array}$ \\
\hline \multicolumn{9}{|c|}{ Minimum MTOW case } \\
\hline 313 & 2,119 & 118 & 30 & 0.21 & 18 & 0.06 & 126 & 10.00 \\
\hline 39 & 2,193 & 122 & 30 & 0.20 & 18 & 0.06 & 134 & 10.02 \\
\hline 71 & 2,213 & 123 & 31 & 0.19 & 18 & 0.06 & 133 & 9.51 \\
\hline \multicolumn{9}{|c|}{ Maximum fuel efficiency case } \\
\hline 215 & 2,469 & 137 & 32 & 0.19 & 18 & 0.06 & 148 & 12.44 \\
\hline 207 & 2,518 & 140 & 33 & 0.20 & 18 & 0.06 & 159 & 12.37 \\
\hline 152 & 2,447 & 136 & 32 & 0.21 & 18 & 0.06 & 153 & 12.33 \\
\hline
\end{tabular}

for a cruise segment can be as much as $70 \%-80 \%$ of the power required for the take-off and climb segments. A fixed-wing PAV with hybrid propulsion requires a relatively powerful and heavy IC engine to be able continuously to generate electricity during the cruise phase. Unlike the case of hybrid cars in a highway cruise mode, a fixed-wing PAV with hybrid propulsion has little excess power to be able to charge the batteries when cruising in flight. However, the approximately $20 \%$ increase in the MTOW compared to that of the conventional IC enginebased counterpart appears to be attributable to the increased specific fuel consumption.

Case 64 showed the highest fuel efficiency. To compare the engine efficiency rates of the four different engine types, the PAVs were sized, fixing the engine weight to match that of 
Table 14 Optimized sizing result for various engine types

\begin{tabular}{|c|c|c|c|c|c|c|c|c|c|}
\hline Type & Case & $\begin{array}{l}\text { MTOW } \\
\text { (lb) }\end{array}$ & $\begin{array}{c}\text { Wing } \\
\text { area }\left(f t^{2}\right)\end{array}$ & $\begin{array}{l}\text { Wing span } \\
\text { (ft) }\end{array}$ & $\begin{array}{c}\mathrm{T} / \mathrm{W} \\
(\mathrm{Ib} / \mathrm{lb})\end{array}$ & $\begin{array}{c}\mathrm{W} / \mathrm{S} \\
\left(\mathrm{lb} / f t^{2}\right)\end{array}$ & $\mathrm{P} / \mathrm{W}$ (hp/lb) & $\begin{array}{c}\text { Engine power } \\
\text { (BHP) }\end{array}$ & $\begin{array}{c}\text { Fuel efficiency } \\
\text { (mpg) }\end{array}$ \\
\hline Gasoline & 313 & 2,119 & 118 & 30 & 0.21 & 18 & 0.06 & 126 & 10.00 \\
\hline Diesel & 39 & 2,369 & 132 & 32 & 0.20 & 18 & 0.06 & 143 & 10.30 \\
\hline Hybrid gasoline & 50 & 2,943 & 161 & 35 & 0.21 & 18 & 0.06 & 209 & 8.17 \\
\hline Hybrid diesel & 50 & 3,198 & 175 & 36 & 0.21 & 18 & 0.06 & 229 & 8.34 \\
\hline
\end{tabular}

Case 64. Table 15 compares the fuel efficiency outcomes of PAVs with the four different engine types. Among the four engine types, the two hybrid engines showed inferior fuel efficiency relative to their non-hybrid counterparts. Among the optimum sizing results in Table 14, PAVs with either gasoline or diesel engines were deemed superior to the hybrid gasoline or hybrid diesel PAVs considering the MTOW, wing area and fuel efficiency. The gasoline-engine-based PAV had slightly worse fuel economy than the diesel-based vehicle. However, the gasoline PAV was selected as the final design considering its lower emissions and MTOW outcomes.

Figures 9 and 10 illustrate the selected optimal PAV configurations created in CATIA (Dassault Systemes, 2019).

Table 15 Fuel efficiency based on the same engine weight

\begin{tabular}{lc}
\hline Type & Fuel efficiency $(\mathrm{mpg})$ \\
\hline Gasoline & 13.29 \\
Diesel & 14.97 \\
Hybrid gasoline & 13.12 \\
Hybrid diesel & 14.77 \\
\hline
\end{tabular}

Figure 9 Roadable PAV configuration, drive mode vs flight mode
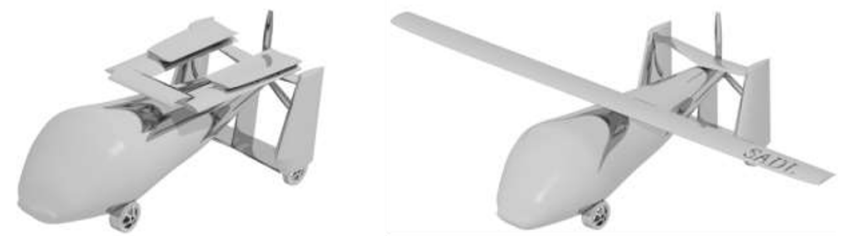

Figure 10 Roadable PAV front and top view dimensions

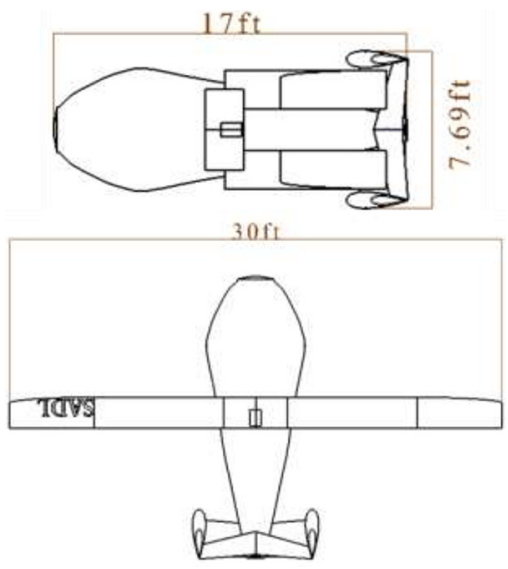

\section{Conclusion}

In this study, a computer program for the initial sizing of roadable PAVs that considers their operability in Korea was developed. Using the program, a roadable PAV concept that meets Korean road transportation regulations was designed. A constraint analysis can be performed using the sizing program based on the defined PAV configuration and mission profile, setting the requirements for the ground roll, rate of climb, max cruise speed, service ceiling and stall constraint. Furthermore, a performance analysis can be conducted for mission segments through aerodynamic, propulsion and weight analyses. The sizing program allows users to set up a DOE table, where various settings of design variables can be automatically populated for the optimal mission profile and sizing results. The DOE table was populated considering the regulations and infrastructure elements of Korea and the FAR PART 23 regulations.

The key design variables for the PAV sizing program are the driving speed, driving distance, flying range, maximum speed, cruising speed, cruising altitude, diversion range, passengers, baggage, take-off ground roll, take-off altitude, rate of climb, rate of climb altitude, stall speed and service ceiling. Among these variables, the take-off ground roll, cruise speed, rate of climb, stall speed, range and cruising altitude showed higher rates of sensitivity to the sizing results. Therefore, a DOE table was created, varying these six variables.

From all of the sizing results obtained by running the DOE table, the results meeting the FAR PART 23 limits and those within the statistical ranges of the single-engine GA aircraft class were selected. The stall speed had the most significant impact on the sizing results.

The sizing results showed that PAVs with hybrid engines had higher MTOWs compared to those with IC engines. Hybrid propulsion-powered PAVs also had a larger wing area, larger wing span and greater engine power, leading to fuel economy penalties. The poor fuel efficiency of hybrid engines led to reduced mission ranges. Unlike automobiles, the weight penalty of the hybrid system due to the additional electrical components reduced the fuel efficiency considerably. When the four engine types were compared, matching the total engine system weight, the IC engine PAVs had better fuel efficiency rates than the hybrid powered PAVs. Finally, a gasoline-powered PAV configuration was selected as the final design because it had the lowest MTOW, despite its slightly worse fuel efficiency compared to that of the diesel-powered engine.

For automobile applications, various hybrid systems have been proven to provide environmental benefits, achieving significantly better fuel economy rates. However, for air vehicles, hybrid engines do not offer a reduction in fuel consumption. Therefore, future work will investigate the potential environmental benefits of electric propulsion using either batteries or fuel cells for environmentally friendly PAVs. 


\section{References}

Aerocar (2019), “Aerocar”, available at http://en.wikipedia. org/wiki/Aerocar/ (accessed 6 August 2019).

Brandt, S.A. and Gilliam, F.T. (1995), "Design analysis methodology for solar-powered aircraft", fournal of Aircraft, Vol. 32 No. 4, pp. 703-709.

Brown, A. and Harri, L. (2018), "A vehicle design and optimization model for on-demand aviation", AIAA/ASCE/ AHS/ASC Structures, Structural Dynamics, and Materials and Conference, 8-12 January, Kissimmee, FL.

Burden, R. and Faires, J. (2011), Numerical Analysis, Brooks Cole Pub.

Cambone, S.A., Krieg, K.J., Pace, P. and Wells, L. (2005), Unmanned Aircraft Systems Roadmap 2005-2030, US Dept. of Defence, Washington, DC.

Carplane (2019), "Carplane", available at: www.carplane.de/ (accessed 6 August 2019).

Carter, J. (2000), "CarterCopter - a high technology gyroplane", American Helicopter Society Vertical Lift Aircraft Design Conference, 19-21 January, San Francisco, CA.

CESSNA 152 (2019), “Cessna 152”, available at www.aopa. org/go-fly/aircraft-and-ownership/aircraft-fact-sheets/cessna152 (accessed 27 October 2019).

Chung, P., Ma, D. and Shiau, J. (2019), "Design, manufacturing, and flight testing of an experimental flying wing UAV", Applied Sciences, Vol. 9 No. 15, p. 3043.

Coronado, P., Cuffie, B., Saer, D. and Zha, G. (2007), "Conceptual design of a personal aerial vehicle using co-flow jet airfoil", 25th AIAA Applied Aerodynamics Conference, 25-28 June, Miami, FL.

Dassault Systemes (2019), "Dassault systemes", available at: www.3ds.com/ko/products-services/catia/ (accessed 6 August 2019)

DIAMOND DA20 (2019), “diamond da20", available at https://www.aopa.org/go-fly/aircraft-and-ownership/aircraftfact-sheets/diamond-da20 (accessed 27 October 2019).

Gokcin, C., Mathias, E. and Dimitri, N.M. (2016), "A methodology for sizing and analysis of electric propulsion subsystems for unmanned aerial vehicles", 54th AIAA Aerospace Sciences Meeting, AIAA SciTech Forum, 4-8 Fanuary, San Diego, CA.

Gudmundsson, S. (2013), General Aviation Aircraft Design Applied Method and Procedures, Butterworth-Heinemann, Oxford.

Hepperle, M. (2012), Electric Flight-Potential and Limitations, German Aerospace Center, Institute of Aerodynamics and Flow Technology, Germany.

Joo, H.J. and Hwang, H.Y. (2017), "Surrogate aerodynamic model for initial sizing of solar high-altitude long-endurance flight", Fournal of Aerospace Engineering, Vol. 30 No. 6.

Kleinbekman, C., Mitici, A. and Wei, P. (2018) "eVTOL arrival sequencing and scheduling for on-Demand urban air mobility", 36th IEEE/AIAA Digital Avionics Systems Conference, 23-27 September, Chelsea, London.

Korea Law Translation Center, Parking Lot Act (2019), "Korea law translation center, parking lot act", available at:
https://elaw.klri.re.kr/eng_service/lawView.do?hseq=6727\& lang=ENG (accessed 18 April 2019).

Korea Ministry of Government Legislation (2015), "Regulations on the structure and facility standards of roads, 22 July".

Li, Y., DeLaurentis, D. and Mavris, D. (2003), "Advanced rotorcraft concept development and selection using a probabilistic methodology", AIAA's 3rd Annual Aviation Technology, Integration, and Operation (ATIO) Forum, 17-19 November, Denver, CO.

Lim, D.W., Justin, C. and Mavris, D. (2015), "Advanced general aviation concept study for a roadable aircraft", 15th AIAA Aviation Technology, Integration, and Operation Conference, 22-26 June, Dallas, TX.

Moore, M. (2006), NASA Personal Air Transportation Technologie, SAE technical paper, NASA Langley Research Center, Langley, August.

Nam, T.W. (2007), "A generalized sizing method for revolutionary concepts under probabilistic design constraint", PhD Thesis, Goergia Institute of Technology, Atlanta, GA.

PAL-V (2019), "Pal-v", available at: www.pal-v.com/ (accessed 6 August 2019).

Raymer, D. (2018), Aircraft Design: A Conceptual Approach, American Institute of Aeronautics \& Ast, New York, NY.

Riboldi, C. and Gualdoni, F. (2016), "An integrated approach to the preliminary weight sizing of small electric aircraft", Aerospace Science and Technology, Vol. 58 No. 2016, pp. 134-149.

Shin, K.S., Hwang, H.Y. and Ahn, J. (2018), "Mission analysis of solar UAV for high-altitude long-endurance flight", fournal of Aerospace Engineering, Vol. 31 No. 3.

Srilatha, R. (2012), Design of a 4-Seat, General Aviation, Electric Aircraft, SJSU Scholarworks, San Jose State University, San Jose, CA.

Terrafugia (2019), “Terrafugia", available at: www.terrafugia. $\mathrm{com} /$ (accessed 6 August 2019).

UIUC Airfoil Coordinates Database (2019), "UIUC airfoil coordinates database", available at: https://m-selig.ae. illinois.edu/ads/coord_database.html (accessed 6 August 2019).

Viken, S., Brooks, F. and Johnson, S. (2006), "Overview of the small aircraft transportation system project four enabling operating capabilities", fournal of Aerospace Engineering, Vol. 43 No. 6, pp. 1602-1612.

Vito, V., Gabard, L., Filippone, E., Morani, G., Tallec, C., Giulietti, F., Gatti, M., Keshales, B., Greenberg, S., Delic, M., Fassois, S., Michaelides, P. and Mastrapostolis, T. (2012), "Automation and control architectures for the personal plane project", AUVSI Israel International Conference, 20-22 March, Tel Aviv, Israel.

Yarygina, M. and Popov, Y. (2012), "Development of the weight formula for a folding wing", Russian Aeronautics (IzVuz), Vol. 55 No. 2, pp. 120-160.

\section{Corresponding author}

Ho-Yon Hwang can be contacted at: hyhwang@sejong.edu 